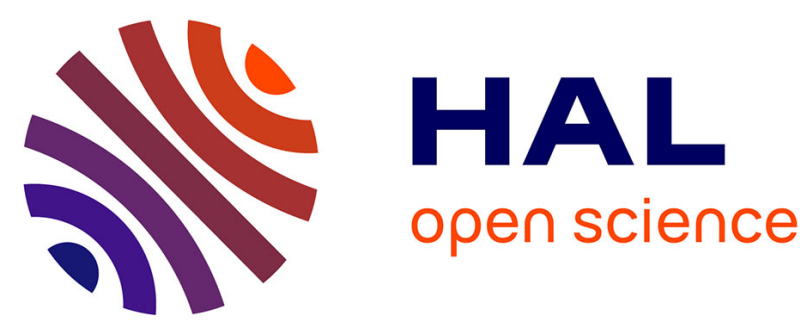

\title{
Deep remission on magnetic resonance imaging impacts outcomes of perianal fistulizing Crohn's disease
}

\author{
Marion Chambaz, Mikael Verdalle-Cazes, Charlotte Desprez, Lucie \\ Thomassin, Cloé Charpentier, Sebastien Grigioni, Laura Armengol-Debeir, \\ Valérie Bridoux, Guillaume Savoye, Céline Savoye-Collet
}

\section{To cite this version:}

Marion Chambaz, Mikael Verdalle-Cazes, Charlotte Desprez, Lucie Thomassin, Cloé Charpentier, et al.. Deep remission on magnetic resonance imaging impacts outcomes of perianal fistulizing Crohn's disease. Digestive and Liver Disease, 2019, 51 (3), pp.358-363. 10.1016/j.dld.2018.12.010 . hal02363668

\section{HAL Id: hal-02363668}

https://hal-normandie-univ.archives-ouvertes.fr/hal-02363668

Submitted on 22 Oct 2021

HAL is a multi-disciplinary open access archive for the deposit and dissemination of scientific research documents, whether they are published or not. The documents may come from teaching and research institutions in France or abroad, or from public or private research centers.
L'archive ouverte pluridisciplinaire HAL, est destinée au dépôt et à la diffusion de documents scientifiques de niveau recherche, publiés ou non, émanant des établissements d'enseignement et de recherche français ou étrangers, des laboratoires publics ou privés.

\section{(ㅇ)(1) $\$$}

Distributed under a Creative Commons Attribution - NonCommerciall 4.0 International 
Deep remission on magnetic resonance imaging impacts outcomes of perianal fistulizing Crohn's disease

Marion Chambaz, MD ${ }^{1}$, Mikael Verdalle-Cazes ${ }^{2}$, Charlotte Desprez, MD ${ }^{1}$, Lucie Thomassin $\mathrm{MD}^{1}$, Cloé Charpentier, MD, ${ }^{1}$, Sébastien Grigioni MD ${ }^{3}$, Laura Armengol-Debeir MD ${ }^{1}$, Valérie Bridoux MD, $\mathrm{PhD}^{4}$, Guillaume Savoye MD $\mathrm{PhD}^{1}$, Céline Savoye-Collet MD, $\mathrm{PhD}^{2}$

${ }^{1}$ Department of Gastroenterology, Rouen University Hospital, Normandie Univ, UNIROUEN, INSERM U1073

${ }^{2}$ Department of Radiology, Rouen University Hospital, Normandie Univ, UNIROUEN, Quantif-LITIS EA 4108

${ }^{3}$ Department of Nutrition, Rouen University Hospital, Normandie Univ, UNIROUEN, INSERM U1073

${ }^{4}$ Department of Surgery, Rouen University Hospital, Normandie Univ, UNIROUEN, INSERM U1073

1 rue de Germont, F-76031, Rouen cedex, France 


\section{Corresponding author:}

Céline Savoye-Collet, MD, PhD

Department of Radiology, Rouen University Hospital Charles Nicolle, 1 rue de Germont, F-

76031, Rouen cedex, France

Tel +33232886496- Fax +33232888235

celine.savoye-collet@chu-rouen.fr

No specific funding has been received

\section{Non-standard abbreviations:}

MRI: magnetic resonance imaging

Crohn's disease: $\mathrm{CD}$

Tumor necrosis factor: TNF

Word count: 2663 


\section{Abstract}

Background: The long-term management of perianal Crohn's disease for patients on antiTNF- $\alpha$ therapy remains challenging.

Aim: To evaluate the long-term course and complications of patients with perianal fistulas treated with anti-TNF- $\alpha$ based on their clinical remission and healing on MRI.

Methods: Patients were evaluated clinically and by MRI. Deep remission was defined as clinical remission associated with the absence of contrast enhancement and T2 hyperintensity on MRI. Flare-free survival, surgery and hospitalizations were compared based on the presence or not of deep remission.

Results: Forty-eight consecutive patients were included with a median follow-up of 62 months after anti-TNF- $\alpha$ first administration. Deep remission was observed in 16 patients $(33.4 \%)$. For patients in deep remission, the median time to any perianal event was 116 months (95-130) versus 42 months (8-72) in patients with pathological MRI $(\mathrm{p}<0.001)$. Sixteen patients $(50 \%)$ with pathological MRI had perianal surgery versus $2(12.5 \%)$ in the deep remission group $(\mathrm{p}<0.05)$. The mean duration of cumulative hospital stays was $0.75 \pm 0.52$ days in the deep remission group versus $19.7 \pm 7.4$ in the pathological group $(\mathrm{p}<$ $0.05)$.

Conclusions: Higher flare-free survival and lower rates of surgery and hospitalization were found in patients achieving deep remission.

Key Words: Crohn's disease ; Magnetic resonance imaging; Anal fistula; anti-TNF- $\alpha$ 


\section{Introduction}

Crohn's disease (CD) is a chronic inflammatory bowel disease. Perianal disease can be a complication of $\mathrm{CD}$ with a major negative effect on patients' quality of life (1). Fistulas, anal fissures, abscesses and anorectal strictures occur in one-third of patients with $\mathrm{CD}$, either before or after the diagnosis of CD (1-2). The treatment of perianal CD requires combined surgical and medical therapies including antibiotics, anti-tumor necrosis factor (TNF)- $\alpha$ and immunosuppressants (3-12). The use of anti-TNF- $\alpha$ deeply improves the management of perianal CD. Anti-TNF- $\alpha$ have demonstrated their efficacy as induction therapy and also as maintenance therapy in disease remission $(6,13)$. The first placebo-controlled trial with infliximab as induction therapy showed complete closure of fistulas in 50\% of patients (6). Immunosuppressors and duration of seton drainage are also associated with better outcomes (14). Maintenance therapy is necessary to increase sustained response and patients require dose adjustments (7). Initial doses could be intensified or decreased, based on clinical response.

Magnetic resonance imaging (MRI) is a highly accurate non-invasive modality and allows morphological assessment and classification of perianal fistulas $(12,15)$. MRI is considered as the gold standard imaging technique. An MRI-based score (Van Assche score) is used to describe the anatomy, complexity and activity of fistulas (16). On MRI, fistula activity is represented by semiological items as contrast enhancement and T2 hyperintensity. Several authors have reported that changes in MRI patterns can be followed (15-19).

Clinically, perianal activity is assessed according to fistula drainage (6). Nevertheless, clinical response often contrasts with fistula healing on MRI (17-19). It has been demonstrated that an active fistula track might persist despite clinical healing (fistula classified as clinically closed) (20). Cessation of treatment following clinical remission but 
before eradication of the track on MRI could be responsible for recurrences. In that regard, combined MRI and clinical evaluation should be preferred to clinical evaluation alone. In luminal $\mathrm{CD}$, deep remission is defined as endoscopic mucosal remission associated with clinical remission. This concept has become a therapeutic goal in emerging treat-to-target approaches. Mucosal healing is associated with lower hospitalization rates, fewer surgical interventions and less relapse (21-22). Fistula healing on MRI could also be considered as a target. There are very limited data regarding the long-term outcomes and complications in CD patients with perianal fistulas in both clinical and MRI remission.

The aim of this study was to evaluate the long-term course and complications of CD patients with perianal fistulas treated with anti-TNF- $\alpha$ based on their clinical remission and healing on MRI.

\section{Materials and Methods}

\section{Subjects}

Between 2000 and 2017, all consecutive patients with fistulizing perianal CD treated with maintenance anti-TNF- $\alpha$ and evaluated by repeated MRI in our tertiary care center, were retrospectively reviewed. This retrospective study, without dedicated intervention, was approved by the Institutional Review Board and informed consent was waived. All patients had a confirmed diagnosis of CD. Patients were diagnosed by clinical, histological, radiological, and endoscopic examinations and had proven history of active perianal fistulas. An initial perianal MRI examination was performed before the induction treatment.

Patients' characteristics (age, sex, smoking status, family history of inflammatory bowel diseases, localizations of disease according to Montreal criteria, mean duration of CD) 
were assessed (23). Patients with an abscess had surgical drainage with setons associated with antibiotics, when appropriate. All patients had at least 12 months of anti-TNF- $\alpha$ therapy. They received induction therapy either with adalimumab (160,80, $40 \mathrm{mg}$ at week 0,2 and 4) or with infliximab (5 mg/kg at weeks 0, 2 and 6). Immunosuppressant drugs could be associated (azathioprine, methotrexate or purinethol). This induction treatment was followed by maintenance therapy $(5 \mathrm{mg} / \mathrm{kg}$ of infliximab every 8 weeks or adalimumab $40 \mathrm{mg}$ every week). Each treatment could be optimized by decreasing the interval between two injections or by increasing doses or could be switched with other biologic drugs in case of failure (i.e. certolizumab, ustekinumab or vedolizumab). Seton removal was usually performed after induction treatment with anti-TNF- $\alpha$ between weeks 6 and 14. However it could be delayed at the appreciation of the clinician in charge in case of significant and persistent leakage.

\section{MRI examination}

An MRI examination was performed in all patients, before the start of anti-TNF- $\alpha$ therapy and then after at least 12 months of anti-TNF- $\alpha$ therapy. MRI examination was performed on a Philips Achieva 1.5 Tesla (Philips Medical Systems, Best, the Netherlands) using a torso phased-array coil. Patients were placed in supine position; the pelvis was centered on the coil. T2-weighted two-dimensional (2D) turbo spin-echo (TSE) sequences $(\mathrm{TR}=6000 \mathrm{~ms}, \mathrm{TE}=500 \mathrm{~ms}, \mathrm{scan}$ time $=5 \mathrm{~min}$, matrix of $312 \times 512$, field of view $250 \mathrm{~mm})$ and T2-weighted 2D TSE sequences with spectral presaturation inversion recovery (SPIR) $(\mathrm{TR}=2000 \mathrm{~ms}, \mathrm{TE}=50 \mathrm{~ms}$, scan time $=5 \mathrm{~min}$, matrix of $312 \times 512$, field of view $250 \mathrm{~mm})$ were obtained. T1-weighted 2D TSE sequences with and without fat suppression with SPIR $(\mathrm{TR}=500 \mathrm{~ms}, \mathrm{TE}=10 \mathrm{~ms}, \mathrm{scan}$ time $=5 \mathrm{~min}$, matrix of $285 \times 384$, field of view $=250 \mathrm{~mm})$ sequences were performed after gadolinium enhancement after checking for normal renal 
function. Coronal and axial planes were oriented using the long axis of the anal canal. MRI evaluations were assessed by experienced gastrointestinal radiologists by retrieving images from the Institutional Picture Archiving and Communicating System. Each item was evaluated according to Van Assche score (16). Complexity of the fistula tracks (single unbranched: 1, single branched: 2, multiple: 3); location regarding the sphincter (inter/extrasphincteric: 1, transsphincteric: 2, suprasphincteric: 3); extension (infralevatoric: 1, supralevatoric: 2); hyperintense appearance in T2-weighted sequences (absent: 0, mild: 4,

pronounced: 8); presence of abscesses (hyperintense fluid collections $>3 \mathrm{~mm}$ in T2-weighted sequences: 4), and rectal wall involvement (thickened rectal wall: 2) were recorded. In addition, fistula enhancement after gadolinium injection was analyzed as present or absent.

\section{Clinical and MRI evaluations}

The fistula drainage assessment has been utilized to standardize the clinical assessment according to Present's criteria (6). Drainage of fistula openings was studied under gentle finger compression and identified as open and actively draining or closed. Clinical remission was defined as the absence of persisting draining fistulas self-reported by the patient or the absence of any draining fistulas at examination. Clinical examination was performed by a senior gastroenterologist specialized in inflammatory bowel disease (IBD). All clinical examinations were performed by the same physician dedicated to one patient.

MRI interpretation was performed by a senior gastrointestinal radiologist (18 years of experience). Healing on MRI was defined as the total disappearance of T2 hyperintensity and contrast enhancement after gadolinium injection, along the entire fistula track; otherwise, it was considered as pathological on MRI. 
Clinical and MRI evaluations were assessed and patients were classified either in the deep remission group or not. Deep remission was defined as the association of both clinical remission according to Present criteria and healing on MRI.

\section{Outcomes}

All reports mentioning the flare of luminal and perianal CD were reviewed. Flare was defined as the appearance or exacerbation of symptoms for over 2 consecutive weeks leading to an unscheduled visit to the out-patient clinic with or without therapeutic intervention or changes. All surgeries, as well as the number and duration of hospital stays were collected. Discontinuation, optimization (increase in dosage) or changes (switch of drugs or addition of drugs) in CD-related treatment were also collected. An event was defined as flare, hospitalization, surgery, optimization or switch of therapy. We identified the cause of the event as perineal or luminal according to symptoms.

\section{Statistical analysis}

Qualitative data are described as percentage and quantitative data as median and maximal range values. The events were analyzed using survival analysis (Kaplan Meier test) and compared using Log Rank test (Mantel Cox). Comparison of patients according to their

deep remission status was made by $\mathrm{Chi}^{2}$ test for qualitative and Fisher test for quantitative variables. Results were considered significant with a $\mathrm{p}$ value of $<0.05$. 


\section{Results}

\section{Patients' characteristics}

Forty-eight patients were included. Their characteristics are listed in Table 1. Of these 48 patients, 30 were female. The median age was 32 years (14-70) and the mean duration of CD was 72 months (3-300 months). According to the Montreal classification, 6 patients (12\%) were diagnosed with a penetrating complication (B3) (23). Forty-five percent of the patients had ileo-colitis involvement (L3) at the time of diagnosis. Pure colonic disease was observed in 16 patients (33\%) and isolated ileal location in $4(8 \%)$. All patients had received anti-TNF- $\alpha$ therapy for at least 12 months before MRI and clinical evaluation, with a median treatment duration of 26 months (12-85) (Table 1).

\section{Clinical and MRI evaluation}

Thirty-two patients had pathological MRI. Among them, the median Van Assche score was 12 (2-19). The MRI characteristics of these patients are listed in Table 2. The most common fistula location was extra or inter-sphincteric (75\%) and thirteen patients had an abscess. Sixteen patients had healing on MRI (Figure 1) and were considered to be in clinical remission. Ten patients were in clinical remission despite pathological MRI. There was no difference in patients' characteristics regarding the presence or absence of deep remission (Table 1). 


\section{Flare-free survival course}

The median follow-up period was 62 months $(5$ - 130). In patients with deep remission, the median time to a flare event was 96 months (69-116) versus 12 months (3-20) in patients with pathological MRI ( $\mathrm{p}<0.01$ ), (Figure 2). In patients with deep remission, five events were observed; three patients had clinical perianal recurrence, one patient had an allergy to infliximab and one patient had luminal recurrence. Three patients in deep remission were lost to follow-up at 17, 61 and 130 months, respectively. In the pathological MRI group, 26 patients had an event; seventeen had perianal relapse and nine luminal recurrence. Two patients were lost to follow-up at 3 and 29 months, respectively.

\section{Perineal flare-free survival course}

In patients with deep remission, the median time to any perianal event was 116 months (95-130) versus 42 months (8-72) in patients with pathological MRI ( $<<0.001)$, (Figure 3). Among patients in deep remission, three patients had clinical perianal recurrence at 26, 41 and 64 months, respectively. In the pathological MRI group, seventeen patients had perianal relapse.

\section{Treatment during follow-up}

All sixteen patients in deep remission were treated with infliximab. Three of them received adalimumab during their follow-up for perianal relapse, luminal recurrence and allergy to infliximab, respectively. Certolizumab was introduced in one patient due to antiTNF- $\alpha$ intolerance. Five patients benefited from reduced dosage and three patients 
discontinued treatment. Two of the three patients had perianal relapse after discontinuation. Among the group of patients with pathological MRI, 16 received infliximab and 16 were on adalimumab. Among the 16 patients on adalimumab, 12 were switched due to infliximab failure. Fourteen patients (44\%) were optimized compared with $3(13 \%)$ in the deep remission group $(\mathrm{p}<0.05)$, (Table 3$)$. Sixteen patients $(50 \%)$ with pathological MRI had perianal surgery compared with $2(12.5 \%)$ in the deep remission group $(\mathrm{p}<0.05)$, (Table 3$)$.

\section{Hospitalizations}

The mean number of hospital stays was $0.53 \pm 0.35$ in the deep remission group versus $2.6 \pm 0.5$ in the pathological MRI group $(\mathrm{p}<0.05)$. The mean duration of cumulative hospital stays was $0.75 \pm 0.52$ days in the deep remission group versus $19.7 \pm 7.4$ days in the pathological MRI group ( $<$ 0.05), (Figure 4).

\section{Discussion}

In this study, 48 patients with perianal CD on anti-TNF- $\alpha$ treatment were followed for a median of 62 months. Flare-free and perianal event-free survival were statistically longer in patients with deep remission compared to patients with pathological MRI. Patients with pathological MRI needed four times more perianal surgeries than patients with deep remission. Deep remission also positively impacted the need for treatment changes and hospitalization.

One third of patients were in deep remission after at least twelve months of anti-TNF$\alpha$ therapy. This rate is comparable to other studies $(15,17-18)$. Ten among the 32 patients with 
pathological MRI were in clinical remission. This clinical-radiography discrepancy is consistent with previous studies. Nevertheless, other studies defined MRI healing without considering contrast enhancement and reported only the disappearance of $\mathrm{T} 2$ hyperintensity on treatment (16-19). In previous studies from our center, we reported deep remission in nearly one third of patients and one third of patients in clinical remission had persisting active fistula tract on MRI $(24,25)$. We described MRI healing as disappearance of T2 hyperintensity and absence of contrast enhancement $(24,25)$. Indeed, contrast enhancement allows a distinction between inflammatory or fibrotic lesions and disappearance of contrast enhancement is related to clinical activity (24-28). Van Assche score appeared insufficient in the setting of anti-TNF- $\alpha$ evaluation; most of the items are linked to anatomical description and to complications of fistula tracks. As a consequence, we decided not to include the Van Assche score as part of our definition of MRI-based deep remission. In this study we did not use magnetization transfer or diffusion to monitor sub-clinical levels of perianal fistulas that have been recently reported as able to help lesion monitoring (29-30).

In this study, patients having achieved deep remission had better prognosis in terms of relapse and hospitalizations. Nearly half of the patients with pathological MRI had treatment optimization versus only $13 \%$ of patients in deep remission. This is one of the first studies to evaluate the long-term outcomes of patients with perianal $\mathrm{CD}$ according to their MRI and clinical evaluation after at least one year of treatment for perianal CD.

In luminal $\mathrm{CD}$, deep remission has proved its interest (31). There are studies that have specifically investigated the long-term outcomes of patients who achieved deep remission in luminal CD. In the EXTENT study, a double-blind placebo controlled trial of adalimumab for the induction and maintenance of mucosal healing in ileocolonic $\mathrm{CD}$, deep remission was assessed at week 12 in eleven patients (32). No patient in deep remission underwent surgery or hospitalization. Nine patients in the non-deep remission group were hospitalized and three 
patients required surgeries. A subsequent analysis of the ACCENT-1 study, suggested that mucosal healing and deep remission increased the duration of clinical remission and the time to clinical relapse (33). The STORI trial, a prospective multicenter study investigated infliximab withdrawal with continuation of azathioprine in patients with luminal $\mathrm{CD}$ in clinical and biological remission. Deep remission was associated with a reduced risk of relapse when infliximab was stopped (34).

In perianal $\mathrm{CD}, \mathrm{Ng}$ et al described deep remission in $30 \%$ of 26 patients by 6 months. No relapse was observed at 12 months and 18 months, and 2 patients stopped their treatment at 6 months without any relapse (17). Tozer et al followed 41 patients for 3 years. Fifteen of these 41 patients assessed were in deep remission by 12 months (20). Seven of the deep remission group relapsed. Relapses were observed in cases of treatment reduction or discontinuation. In our study, treatment reduction (dose reduction or immunosuppressant withdrawal) was performed in $29 \%$ of patients with deep remission. No relapse was observed. Nevertheless, among three patients in deep remission who benefited from a therapeutic break, two patients relapsed. Therefore, drug de-escalation could be discussed in deep remission patients, with regular MRI to detect sub-clinical relapses. However, therapy discontinuation can not be recommended at this present time (35). Moreover, recent data suggest that monitoring drugs through levels could be useful to optimize anti-TNF- $\alpha$ therapy. Yarur et al showed a significant association between serum infliximab levels and rates of fistula healing (36).

Despite its strengths, our study has some limitations related to its retrospective design and small cohort size. Furthermore, we did not evaluate perianal activity using standardized scores as the perianal disease activity index (PDAI). Trough levels were not available at the time of MRI in patients in deep remission and could not be analyzed in our cohort. Moreover, due to the retrospective design of the study cohort the impact of perianal fistulas on quality of 
life were not evaluated. But others have suggested that disease control has a strong impact on quality of life and patient-related outcomes (37). The recently developed Disease Disability Index (IBD-DI) may also help to evaluate the disease burden in these challenging clinical situations (38).

In conclusion, our findings show that perianal deep remission based on MRI, is associated with better long-term outcomes of disease. Achieving deep remission seems to be a relevant target in the management of patients with fistulizing perianal $\mathrm{CD}$. The timing of $\mathrm{MR}$ evaluation needs to be addressed and the next step will be to implement MR monitoring of fistulizing $\mathrm{CD}$ in our daily practice. We believe that MRI-based decisions could be helpful to adjust therapy in a treat-to-target approach. However, it seems dangerous to recommend deescalation therapy based on MRI findings without prospective evidence to support this practice.

\section{Acknowledgments}

The authors are grateful to Nikki Sabourin-Gibbs, Rouen University Hospital, for her help in editing the manuscript. 


\section{References}

1. Schwartz DA, Loftus EV, Tremaine WJ, et al. The natural history of fistulizing Crohn's disease in Olmsted County, Minnesota. Gastroenterology 2002; 122: 875-880

2. Cosnes J, Gower-Rousseau C, Seksik P, Cortot A. Epidemiology and natural history of inflammatory bowel diseases. Gastroenterology 2011;140:1785-94

3. Schwartz DA, Ghazi LJ, Regueiro M, et al. Guidelines for the multidisciplinary management of Crohn's perianal fistulas: summary statement. Inflamm Bowel Dis 2015;21:723-30.

4. Jakobovits J, Schuster MM. Metronidazole therapy for Crohn's disease and associated fistulae. Am J Gastroenterol 1984;79:533-40.

5. Dejaco C, Harrer M, Waldhoer T, et al. Antibiotics and azathioprine for the treatment of perianal fistulas in Crohn's disease. Aliment Pharmacol Ther 2003;18:1113-20.

6. Present DH, Rutgeerts $\mathrm{P}$, Targan $\mathrm{S}$, et al. Infliximab for the treatment of fistulas in patients with Crohn's disease. N Engl J Med 1999;340:1398-405.

7. Sands BE, Anderson FH, Bernstein $\mathrm{CN}$, et al. Infliximab maintenance therapy for fistulizing Crohn's disease. N Engl J Med 2004;350:876-85.

8. Colombel J-F, Sandborn WJ, Rutgeerts P, et al. Adalimumab for maintenance of clinical response and remission in patients with Crohn's disease: the CHARM trial. Gastroenterology 2007;132:52-65.

9. Sandborn WJ, Rutgeerts P, Enns R, et al. Adalimumab induction therapy for Crohn disease previously treated with infliximab: a randomized trial. Ann Intern Med 2007;146:829-38.

10. Colombel JF, Sandborn WJ, Reinisch W, et al. Infliximab, azathioprine, or combination therapy for Crohn's disease. N Engl J Med 2010;362:1383-95. 
11. Sciaudone G, Di Stazio C, Limongelli P, et al. Treatment of complex perianal fistulas in Crohn disease: infliximab, surgery or combined approach. Can J Surg J Can Chir 2010;53:299-304.

12. Gecse KB, Sebastian S, Hertogh G de, et al. Results of the Fifth Scientific Workshop of the ECCO [II]: Clinical Aspects of Perianal Fistulising Crohn's Disease-the Unmet Needs. J Crohns Colitis 2016;10:758-65.

13. Ford AC, Sandborn WJ, Khan KJ, et al. Efficacy of biological therapies in inflammatory bowel disease: systematic review and meta-analysis. Am J Gastroenterol 2011; 106: 644-659

14. Bouguen G, Siproudhis L, Gizard E, et al. Long-term outcome of perianal fistulizing Crohn's disease treated with infliximab. Clin Gastroenterol Hepatol 2013; 11: 975-981

15. D Tougeron, G Savoye, C Savoye-Collet, et al. Predicting factors of fistula healing and clinical remission after infliximab-based combined therapy for perianal fistulizing Crohn's disease. Dig Dis Sci 2009;54:1746-52

16. Van Assche G, Vanbeckevoort D, Bielen D, et al. Magnetic resonance imaging of the effects of infliximab on perianal fistulizing Crohn's disease. Am J Gastroenterol 2003;98:332-339.

17. Ng SC, Plamondon S, Gupta A, et al. Prospective evaluation of anti-tumor necrosis factor therapy guided by magnetic resonance imaging for Crohn's perineal fistulas. Am J Gastroenterol 2009;104:2973-86.

18. Bell SJ, Halligan S, Windsor ACJ, et al. Response of fistulating Crohn's disease to infliximab treatment assessed by magnetic resonance imaging. Aliment Pharmacol Ther $2003 ; 17: 387-93$.

19. Karmiris K, Bielen D, Vanbeckevoort D, et al. Long-term monitoring of infliximab therapy for perianal fistulizing Crohn's disease by using magnetic resonance imaging. Clin Gastroenterol Hepatol Off Clin Pract J Am Gastroenterol Assoc 2011;9:130-6. 
20. Tozer, P. et al. Long-term MRI-guided combined anti- TNF- $\alpha$ and thiopurine therapy for Crohn's perianal fistulas. Inflamm Bowel Dis 2012; 18, 1825-1834.

21. Baert F, Moortgat L, Van Assche G, et al. Mucosal healing predicts sustained clinical remission in patients with early-stage Crohn's disease. Gastroenterology 2010;138:463-468

22. Colombel J-F, Louis E, Peyrin-Biroulet L, et al. Deep remission: a new concept? Dig Dis Basel Switz 2012;30 Suppl 3:107-11.

23. Satsangi J, Silverberg MS, Vermeire S, et al. The Montreal classification of inflammatory bowel disease: controversies, consensus, and implications. Gut 2006;55:749-53.

24. Savoye-Collet C, Savoye G, Koning E, et al. Fistulizing perianal Crohn's disease : contrast-enhanced magnetic resonance imaging assessment at 1 year on maintenance antiTNF alpha therapy. Inflamm Bowel Dis 2011;17:1751-58

25. Thomassin L, Armengol Debeir L, Charpentier C, et al. MRI may predict deep remission in patients with perianal fistulizing Crohn's disease. WJG 2017;23:4285-4292

26. Rimola J, Planell N, Rodríguez S, et al. Characterization of inflammation and fibrosis in Crohn's disease lesions by magnetic resonance imaging. Am J Gastroenterol 2015; 110: 432440

27. Savoye G, Savoye-Collet C. How deep is remission in perianal Crohn's disease and do imaging modalities matter? Am J Gastroenterol 2010;105:1445-1446

28. Horsthuis K , Lavini C , Bipat S, et al. Perianal Crohn disease: evaluation of dynamic contrast enhanced MR imaging as an indicator of disease activity. Radiology 2009; 251: 380 7

29. Dohan A, Taylor S, Hoeffel C, et al. Diffusion-weighted MRI in Crohn's disease: Current status and recommendations. J Magn Reson Imaging 2016;44:1381-96. 
30. Pinson C, Dolores M, Cruypeninck $\mathrm{Y}$, et al. Magnetization transfer ratio for the assessment of perianal fistula activity in Crohn's disease. Eur Radiol 2017;27:80-7.

31. Pineton de Chambrun G, Blanc P, Peyrin-Biroulet L. Current evidence supporting mucosal healing and deep remission as important treatment goals for inflammatory bowel disease. Expert Rev Gastroenterol Hepatol 2016;10:915-927

32. Colombel JF, Rutgeerts PJ, Sandborn WJ et al. Adalimumab induces deep remission in patients with Crohn's disease. Clin Gastroenterol Hepatol 2014;12:414-22.

33. D’Haens G, Noman M, Baert F et al. Endoscopic healing after infliximab treatment for Crohn's disease provides a longer time to relapse. Gastroenterology 2002;122:A-618

34. Louis E, Mary JY, Vernier-Massouille G et al. Maintenance of remission among patients with Crohn's disease on antimetabolite therapy after infliximab therapy is stopped. Gastroenterology 2012;142:63-70

35. Legué C, Brochard C, Bessi G, et al. Outcomes of Perianal Fistulising Crohn's Disease Following Anti-TNFa Treatment Discontinuation. Inflamm Bowel Dis 2018;24 : 1107-1113

36. Yarur AJ, Kanagala V, Stein DJ, et al. Higher infliximab trough levels are associated with perianal fistula healing in patients with Crohn's disease. Aliment Pharmacol Ther 2017;45:933-40.

37. Leong RW, Huang T, Ko Y, et al. Prospective validation study of the International Classification of Functioning, Disability and Health score in Crohn's disease and ulcerative colitis. J Crohns Colitis 2014;8:1237-45.

38. Gower-Rousseau C, Sarter H, Savoye G, et al. Validation of the Inflammatory Bowel Disease Disability Index in a population-based cohort. Gut 2017;66:588-96. 


\section{Figure legends}

Fig.1- Comparison of initial (a) and follow-up (b) MRI of a patient with Crohn's disease on treatment and in clinical remission:

T2-weighted sequences at the same anatomical level: (a) presence of an initial hyperintense fistula (arrow) and (b) disappearance of hyperintensity on follow-up imaging (arrow)

Fig.2 : Flare-free survival (any kind of clinical event)

Fig.3- Perineal flare-free survival

Fig.4- Hospitalizations (stay and duration) based on presence or absence of deep remission in patients with Crohn's disease 


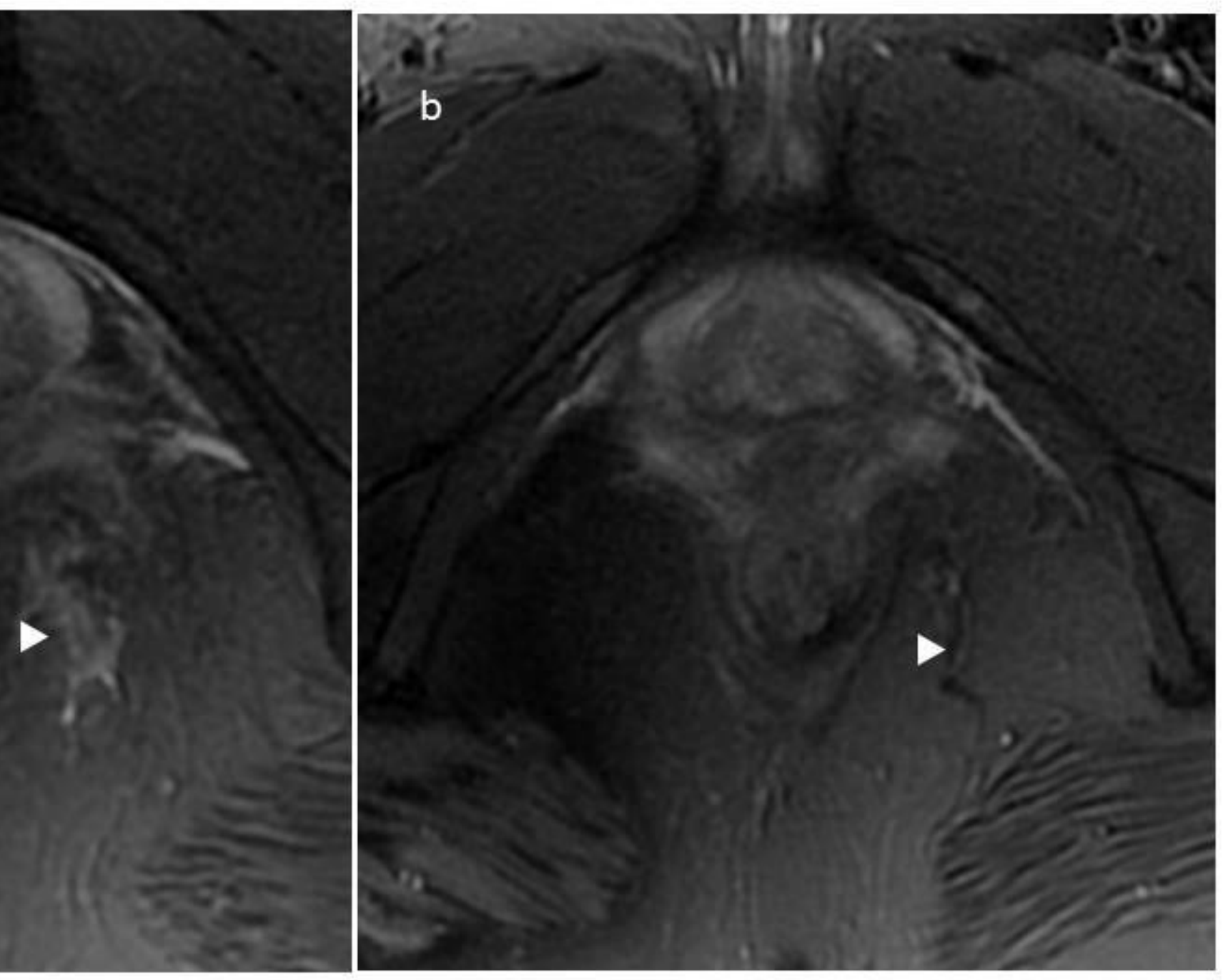




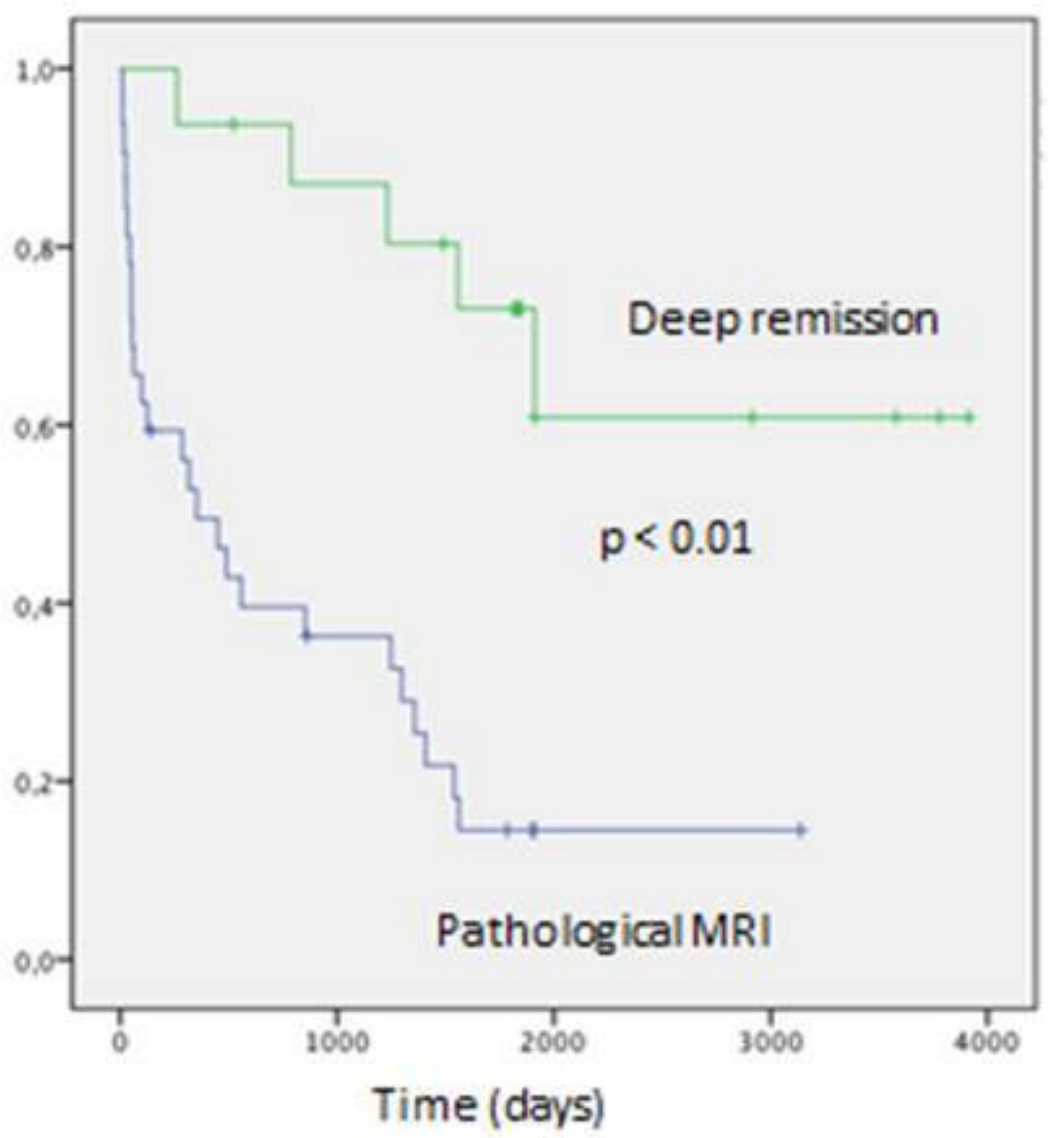

Flare free survival (any kind of clinical event) 


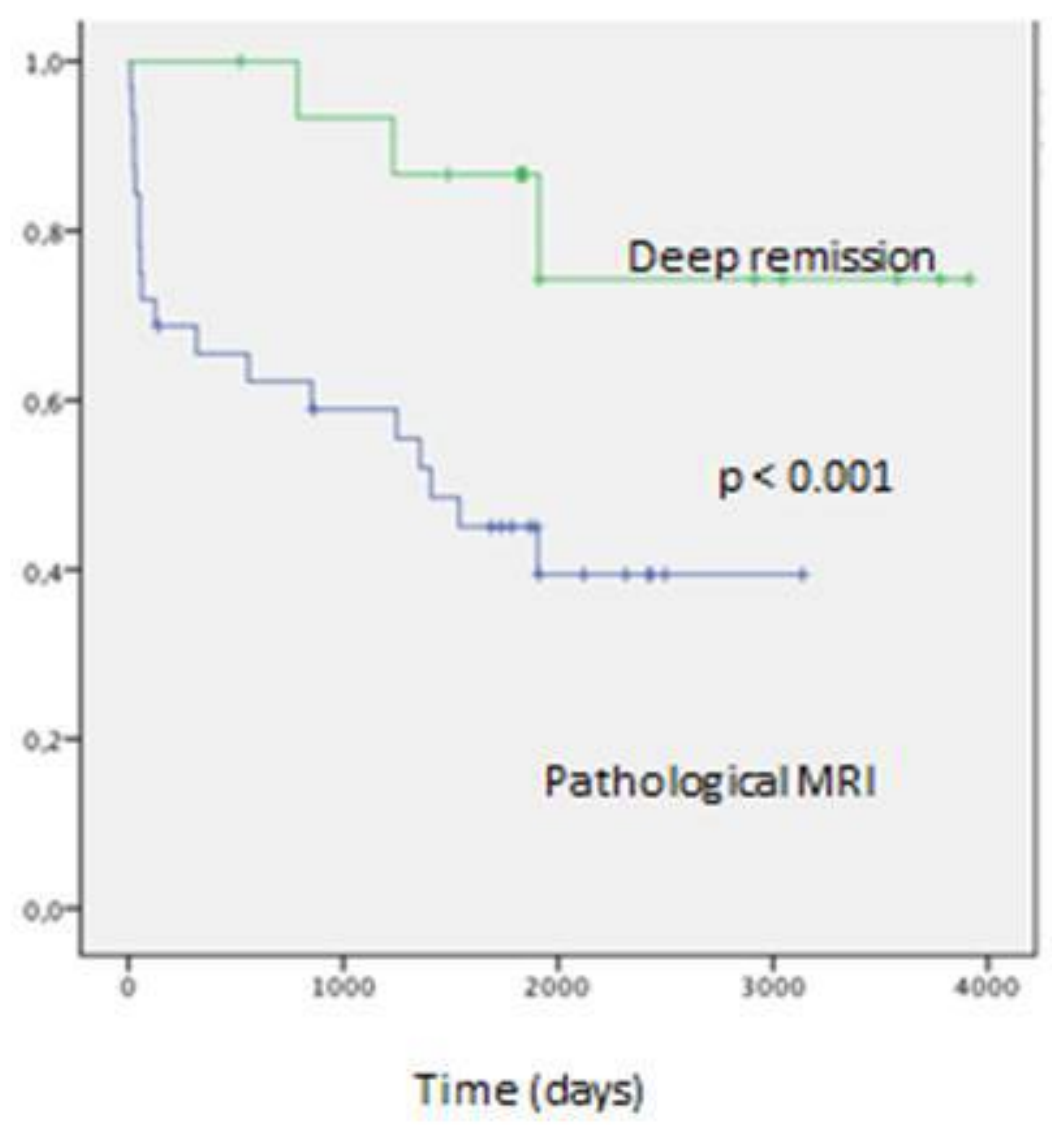

Perineal flare free survival 
Hospitalizations (n)

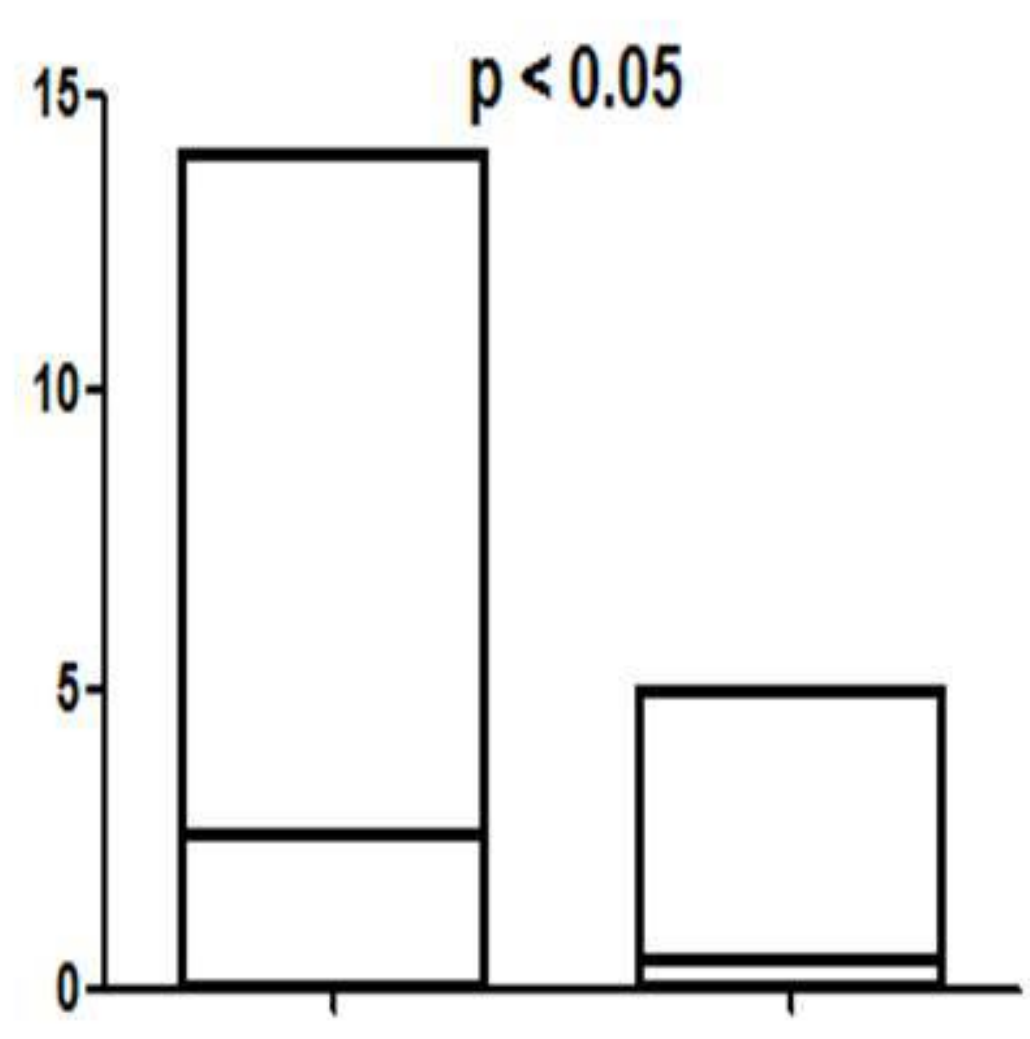

A

B

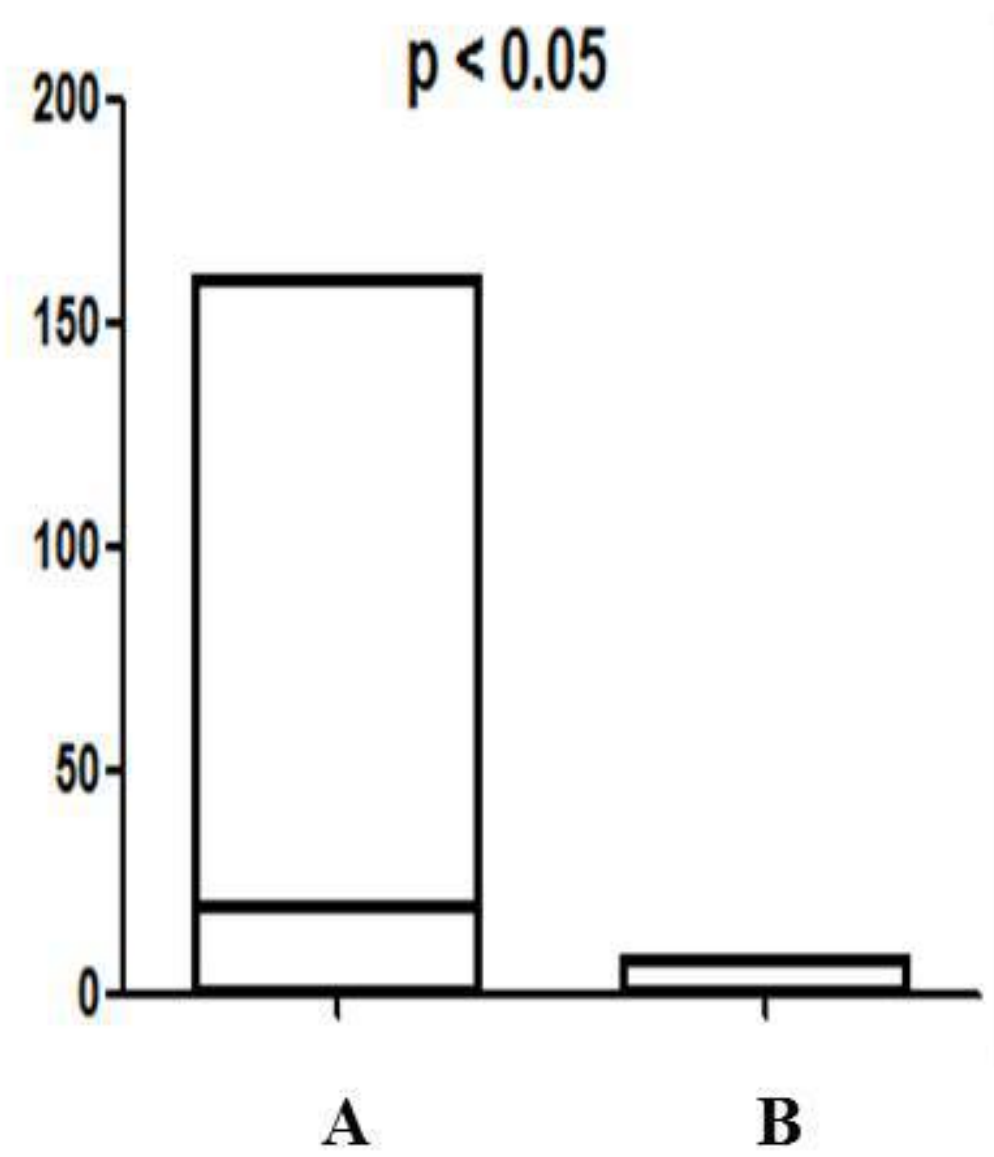

A : Patients with a pathological MRI $(n=32), B$ : Patients in deep remission $(n=16)$ 
Table 1 : Patients's characteristics - n (\%)

\begin{tabular}{|c|c|c|c|}
\hline & \multicolumn{3}{|c|}{$\begin{array}{l}\text { Pathological MRI Deep Remission Patients } \\
\begin{array}{lll}(n=32) & (n=16) & (n=48) \\
\end{array}\end{array}$} \\
\hline Males, n (\%) & $12(37.5)$ & $6(37.5)$ & $18(37.5)$ \\
\hline Females, n (\%) & $20(66.7)$ & $10(62.5)$ & $30(62.5)$ \\
\hline Age yr (median, extreme) & $31(14-70)$ & $33(24-57)$ & $32(14-70)$ \\
\hline Family history of IBD (\%) & $2.0(6.2)$ & $2(12.5)$ & $4(8.3)$ \\
\hline Smoking, $\mathrm{n}(\%)$ & $16(50)$ & $3(18.8)$ & $19(39)$ \\
\hline \multicolumn{4}{|l|}{ Location n (\%) } \\
\hline L1 ileal & $2(6)$ & $2(13)$ & $4(8)$ \\
\hline L2 colonic & $12(37,5)$ & $4(25)$ & $16(33)$ \\
\hline L3 ileocolonic & $12(37,5)$ & $9(56)$ & $21(45)$ \\
\hline $\mathrm{L} 2$ or L3 + L4 upper disease & $6(19)$ & $1(6)$ & $7(15)$ \\
\hline \multicolumn{4}{|l|}{ Disease behavior, $\mathrm{n}(\%)$} \\
\hline B1 non-penetrating non-stricturing & $24(75)$ & $11(69)$ & $35(73)$ \\
\hline B2 stricturing & $4(12,5)$ & $3(19)$ & $7(15)$ \\
\hline B3 penetrating & $4(12,5)$ & $2(12)$ & $6(12)$ \\
\hline Anti TNF- $\alpha(\%)$ & $32(100)$ & $16(100)$ & $48(100)$ \\
\hline Median treatment duration, mo (extreme) & $24(12-63)$ & $30(12-85)$ & $26(12-85)$ \\
\hline Infliximab (\%) & $26(81)$ & $16(100)$ & $42(88)$ \\
\hline Median treatment duration, mo (extreme) & $18(1-63)$ & $30(12-85)$ & $23(1-85)$ \\
\hline Adalimumab (\%) & $17(53 \%)$ & $2(13 \%)$ & $19(40 \%)$ \\
\hline Median treatment duration, mo & $21(1-57)$ & $4(1-8)$ & $21(1-57)$ \\
\hline Optimization & $20(63 \%)$ & $6(38 \%)$ & $26(54 \%)$ \\
\hline Associated immunosupressant drug & $20(63 \%)$ & $13(81 \%)$ & $33(69 \%)$ \\
\hline Perianal surgery & $28(88 \%)$ & $15(94 \%)$ & $40(83 \%)$ \\
\hline
\end{tabular}


Table 2 : MRI characteristics of patients with a pathological MRI

\begin{tabular}{ll}
\hline & $\begin{array}{l}\text { Pathological MRI } \\
\mathrm{n}=32\end{array}$ \\
\hline Van Assche score (mean) & 12 \\
Simple fistula & $23(71.8)$ \\
Ramified fistula & $7(21.9)$ \\
Multiple fistula & $2(6.3)$ \\
Inter/extrasphincteric fistula & $24(75)$ \\
Transsphincteric fistula & $14(43.8)$ \\
Suprasphincteric fistula & $1(3)$ \\
Supralevatoric extension & $3(9.7)$ \\
Abscess & $13(40.6)$ \\
Rectal involvement & $13(41.9)$ \\
T2 hyperintensity & $27(84.4)$ \\
Enhancement & $32(100)$ \\
Anorecto-vaginal fistula & $3(9.4)$
\end{tabular}


Table 3 : Treament during follow up

\begin{tabular}{lcccc} 
& Pathological MRI & Deep remission & Total & \\
& $\mathbf{n}=\mathbf{3 2}$ & $\mathbf{n}=\mathbf{1 6}$ & $\mathbf{n}=\mathbf{4 8}$ & \\
\hline Infliximab, $\mathbf{n}(\%)$ & $16(50)$ & $16(100)$ & $32(67)$ & $\mathrm{p}<0.05$ \\
Median treatment duration, mo (extreme) & $49(1-84)$ & $60(1-120)$ & $58(1-120)$ & \\
Adalimumab, $\mathrm{n}(\%)$ & $24(75)$ & $3(19)$ & $27(57)$ & $\mathrm{p}<0.05$ \\
Median treatment duration, mo (extreme) & $45(1-105)$ & $12(10-96)$ & $44(1-105)$ & \\
\hline Optimization $\mathrm{n}(\%)$ & $14(44)$ & $3(13)$ & $16(33)$ & $\mathrm{p}<0.05$ \\
Associated immunosupressant drug n (\%) & $9(28)$ & $1(6)$ & $10(21)$ & \\
Switch n (\%) & $12(38)$ & $2(13)$ & $14(29)$ & $\mathrm{p}<0.01$ \\
\hline Discontinuation or reduce therapy $\mathrm{n}(\%)$ & $5(16)$ & $9(56)$ & $14(29)$ & $\mathrm{p}<0.01$ \\
\hline Perianal surgery $\mathrm{n}(\%)$ & $16(50)$ & $2(12.5)$ & $18(37.5)$ & $\mathrm{p}<0.05$ \\
Luminal surgery $\mathrm{n}(\%)$ & $8(25)$ & 0 & $8(16.7)$ & \\
\hline
\end{tabular}

